\title{
Análise microbiológica da água do rio Poti no perímetro urbano do município de Teresina, Piauí
}

Gilmara Vieira Fortes Batista ${ }^{1}$, Gustavo Cardoso da Silva ${ }^{1}$, Gerson Tavares Pessoa ${ }^{2}$, Renan Paraguassu de Sá Rodrigues ${ }^{2}$, Maria Angélica Parentes da Silva Barbosa ${ }^{2}$, Marina Pinto Sanches ${ }^{2}$, Kamila Araujo de Mesquita ${ }^{1}$, Maria das Graças Prianti ${ }^{1}$

${ }^{I}$ Faculdade de Ciências Tecnológica de Teresina-CET, Av. João XXIII, São Cristóvão, CEP: 64045-000, Teresina-PI, Brasil.

${ }^{2}$ Universidade Federal do Piauí-UFPI, Centro de Ciências Agrárias, Campus da Socopo Rua Edvaldo Reynaldo, Ininga, CEP: 64049-550, Teresina-PI, Brasil

*Autor para correspondência: gersonpessoa@hotmail.com

RESUMO. Teresina é uma cidade emoldurada por dois rios que a abraça. Por meio disso, a capital do Piauí foi crescendo aceleradamente e desordenadamente, resultando em uma disseminação do lixo no solo e na água. Para o conhecimento do estado de poluição bacteriológica do rio Poti, Estado do Piauí (Brasil) foram coletadas amostras de água em três pontos distintos. Em seguida, foi determinada a quantidade de bactérias totais $/ \mathrm{ml}$; índice de coliformes $/ 100 \mathrm{ml}$, em caldo lactosado, verde brilhante-bile e E.C. (Escherichia coli) e em ágar seletivos, como BEM (Eosin methylene blue) e S.S. (Shigella Samonella). Os resultados mostraram que os índices bacterianos de poluição do rio se tornaram um problema de saúde pública, sendo inevitável rever atividades que possuem implicações que acabam diretamente ou indiretamente degradando os recursos hídricos. Além disso, existe uma importância e urgência em se implantar um eficiente sistema de saneamento básico para toda a população de Teresina, a fim de que todos tenham acesso à água tratada para consumo, diminuindo assim, o risco de enfermidades veiculadas por este recurso. Mais estudos, incluindo os de ordem socioeconômica, devem ser realizados para monitorar a qualidade microbiológica do rio Poti, bem como a forma de utilização destas águas pela população local. O presente trabalho teve como objetivo analisar os aspectos microbiológicos da água do Rio Poti na área de pesca de Teresina, avaliando os possíveis riscos aos trabalhadores e consumidores que desfrutam de atividades aquáticas.

Palavras chave: Análise bacteriológica, poluição hídrica

\section{Microbiological analysis of Poti River water in the urban area of the Teresina - Piauí city}

ABSTRACT. Teresina is a framed city of two rivers that embrace it. Thereby, the capital of Piauí has been growing rapidly and erratically, resulting in a spread of waste in soil and water. In order to understand the state of bacteriological contamination of the Poty River, located in the State of Piauí, Brazil, some water samples were collected in 03 separate points of the city. The next step was to determine the amount of total bacteria/ml (pt); coliform rate/100 ml (0.176pt), in lactic broth, Brilliant Green Bile and Escherichia coli in selective agars, such as Eosin methylene blue (E.M.B) and Shigella samonella (S.S). The results displayed that the bacterial pollution levels of the river have become a matter of public health, and therefore, it is inevitable to review some actions that carry implications which directly and indirectly are degrading the hydric resources. Furthermore, there is an importance and urgency in putting in place an efficient basic sanitation system for the whole population of Teresina, in order to all of them have access to treated water to consumption, and so reducing the risk of diseases that are bound to this resource. Further studies, including the socioeconomic kind, must be conducted in order to monitor the microbiological quality of the Poty River, as well as the way of use of 
these waters by the local population. The present work is aimed to analyze the microbiological aspects of the water of the Poty River in the fishing area of Teresina, evaluating the possible risks to the workers and consumers who enjoy this activity.

Keywords: Bacteriological analysis, hydric pollution

\section{Introdução}

Há muito tempo, acreditava-se que a água doce nunca acabaria; entretanto, o aumento da população e a urbanização sem planejamento, o desperdício, a poluição, a distribuição desigual, o consumo entre países e setores econômicos diferentes fazem com que nos dias atuais haja racionamento de água e disseminação de doenças, como consequências desse mau uso da água, tornando o abastecimento desta ainda mais preocupante para novas gerações (Bettega et al., $\underline{2006}$, Moura et al., 2009).

O Conselho Nacional do Meio Ambiente (CONAMA), órgão ambiental competente para definir os procedimentos complementares para o licenciamento ambiental, por meio da resolução de $n^{\text {o }} 396$ de novembro de 2008 afirma que a disposição inadequada de resíduos sólidos constitui uma ameaça à saúde pública e agrava a degradação ambiental, comprometendo a qualidade de vida das populações. O CONAMA dispõe a classificação dos corpos de água e diretrizes ambientais para o seu enquadramento, bem como estabelece as condições e padrões de lançamento de efluentes, e dá outras providências (CONAMA No 357,2005$)$

A água potável precisa atender a critérios de qualidade, de modo a não causar prejuízos à saúde de seus consumidores, devendo possuir um determinado padrão de potabilidade, com limites de tolerância das substâncias presentes na água como meio de garantir as características de qualidade da mesma (Oliveira, 2012).

Segundo as normas da Resolução CONAMA $\mathrm{n}^{\circ} 357$ (2005), as águas doces, salobras e salinas do território nacional são classificadas, segundo a qualidade requerida para os seus usos preponderantes em treze classes de qualidade. Ainda, segundo esta mesma resolução, as águas doces são classificadas em quatro classes distintas, sendo elas: Classe especial: águas destinadas ao abastecimento; para consumo humano, com desinfecção; à preservação do equilíbrio natural das comunidades aquáticas; à preservação dos ambientes aquáticos em unidades de conservação de proteção integral. Classe 1: águas que podem ser destinadas: ao abastecimento; para consumo humano, após tratamento simplificado; à proteção das comunidades aquáticas; à recreação de contato primário, tais como natação, esqui aquático e mergulho; à irrigação de hortaliças que são consumidas cruas e de frutas que se desenvolvam rentes ao solo e que sejam ingeridas cruas sem remoção de película; à proteção das comunidades aquáticas em Terras Indígenas. Classe 2: águas que podem ser destinadas: ao abastecimento; para consumo humano, após tratamento convencional; à proteção das comunidades aquáticas; à recreação de contato primário, tais como natação, esqui aquático e mergulho; à irrigação de hortaliças, plantas frutíferas e de parques, jardins, campos de esporte e lazer, com os quais o público possa vir a ter contato direto; à aquicultura e à atividade de pesca. Classe 3: águas que podem ser destinadas: ao abastecimento; para consumo humano, após tratamento convencional ou avançado; à irrigação de culturas arbóreas, cerealíferas e forrageiras; à pesca amadora; à recreação de contato secundário; à alimentação de animais. Classe 4: águas que podem ser destinadas: à navegação; à harmonia paisagística.

Para Sant'ana et al. (2009), o risco de ocorrência de surtos de doenças veiculadas à água é alto, por função da possibilidade de contaminação bacteriana. Isso porque muitas vezes as águas são captadas em lugares inadequados, como nas proximidades de fossas, de pastagens de animais e de lançamentos de efluentes sem tratamento. Assim, a análise destas águas pode evidenciar um significativo potencial de contaminação. As doenças de veiculação hídrica como a febre tifóide e paratifóide, disenteria bacilar, cólera e gastroenterites são causadas por microrganismos patogênicos de origem entérica, animal ou humana, transmitidas basicamente pela rota fecal e oral, ou seja, são excretados nas fezes de indivíduos infectados e ingeridos na forma de água ou alimentos contaminados.

Segundo o CONAMA (2000), os coliformes termotolerantes são definidos como microrganismos presentes em fezes humanas e de 
animais homeotérmicos, bem comum em solos, plantas ou outras matrizes ambientais que não tenham sido contaminados por material fecal. De acordo com a referida resolução, o padrão estabelecido para balneabilidade é de 1000 coliformes termotolerantes $/ 100 \mathrm{ml}$. A maioria dos microrganismos não traz malefícios à saúde humana, porém alguns são patogênicos, que podem ser de origem bacteriana, viral e parasitaria. É de grande importância o estabelecimento da quantidade de Número Mais Provável (NMP)/100ml de bactérias, pois este é um ótimo indicativo da potabilidade de um corpo d'água (FUNASA, 2009).

A Portaria $\mathrm{n}^{\circ} 518$ do Ministério da Saúde (2004) estabelece que sejam determinados na água, para aferição de sua potabilidade, a presença de coliformes totais e fecais. A mesma portaria recomenda que a contagem padrão de bactérias não deva exceder a 500 Unidades Formadoras de Colônias por 1 mililitro de amostra (500 UFC/ml).

A Contagem Padrão de Bactérias é muito importante durante o processo de tratamento da água, visto que permite avaliar a eficiência das várias etapas do tratamento. Dentre os parâmetros utilizados para qualificar a água estão os físicoquímicos e os microbiológicos (FUNASA, 2009).

Teresina é uma cidade emoldurada por dois rios que a abraça. Por meio disso, a capital do Piauí foi crescendo aceleradamente e desordenadamente, resultando em uma disseminação do lixo no solo e na água (Oliveira, 2012). O rio Poti é de grande importância para a obtenção de pescado e de matéria prima para a construção civil. Com tal crescimento, foi ocorrendo a extração desordenada desses materiais minerais, provocando altos índices de degradação do ambiente. Para agravar ainda mais a situação, o rio também recebe despejos de efluentes de diversas galerias que se lançam durante todo o ano, sendo assim indicadores de uma má qualidade da água (Iwata \& Câmara, 2007).

Dias (2006) relata que os lançamentos de esgotos no rio Poti favorecem o crescimento de aguapés, onde estes diminuem a correnteza do mesmo, gerando condições que propiciam a proliferação de microrganismos patogênicos. A poluição das águas interfere de tal maneira, que acaba prejudicando a sua utilização decorrente da adição de substâncias que, direta ou indiretamente alteram as características físicas e químicas do corpo d'água (Pereira, 2004). Damasceno et al. (2008) relatam que parâmetros como a temperatura, oxigênio dissolvido, nitrogênio, pH (Potência de Hidrogênio), Coliformes fecais e totais revelam o grau de poluição das águas quando associados a atividades antrópicas.

A temperatura elevada nos meses de setembro a dezembro, chamado de "B. R. O. BRO", na cidade, faz com que a população de baixo poder aquisitivo, sem acesso a áreas de lazer, encontre no rio uma opção para suprir tal carência. Além disso, diversas outras atividades como a pesca de subsistência e a extração de material da construção civil são realizadas no rio Poti. Por conta disso é de fundamenta importância a realização do monitoramento frequente da qualidade dessa água no perímetro urbano, para que se evitem problemas de contaminação da população susceptível.

Dessa forma, o presente estudo teve como objetivo analisar o aspecto microbiológico da água do Rio Poti no perímetro da cidade de Teresina-PI, avaliando os possíveis riscos aos trabalhadores que desfrutam direta ou indiretamente de atividades ligadas ao rio. Ainda, busca diagnosticar a presença de Coliformes totais e fecais nas amostras coletadas, classificando a água de acordo com a resolução do CONAMA No 357 (2005).

\section{Material e Métodos}

Para o monitoramento do rio foram definidos três pontos de coleta, sendo eles: Curva São Paulo (P 01), Ponte Juscelino Kubistchek (P 02), e o Encontro das águas (P 03). O trecho estudado compreende a margem direita do rio o Poti, situada entre o Balneário Curvo São Paulo e a foz do Poti, uma área urbanizada no município de Teresina, Estado do Piauí, Brasil.

Foram analisados os parâmetros microbiológicos, físico-químicos da água coletada. A amostra utilizada foi a água bruta do rio Poti, coletada em um recipiente estéril de 75 $\mathrm{cm}^{2}$, a $05 \mathrm{~cm}$ de profundidade, segundo a FUNASA (2009). As amostras coletadas estavam livres de partículas grandes, detritos, folhas ou outro tipo de material acidental.

Imediatamente após a coleta, as amostras foram colocadas ao abrigo de luz solar e mantidas entre 1 e $4^{\circ} \mathrm{C}$, em curto prazo $(<24$ horas) até a entrega ao laboratório de microbiologia clínica da Faculdade Maurício de 
Nassau, unidade Aliança. O transporte destas foi feito utilizando barras de gelo reutilizável. Foram registradas todas as informações de campo como: identificação do ponto de amostragem e sua localização. Foi utilizado o método de tubos múltiplos ou Método do número mais provável (NMP).

Para as confirmações de coliformes utilizaram-se os testes presuntivo e confirmativo. O teste presuntivo foi realizado através da semeadura de volumes determinados da amostra em tubos de caldo lactosado ou caldo lauril triptose. Para o teste confirmativo, foi feita a transferência de cultura de todos os tubos positivos de caldo lactosado incubados para tubos contendo C.L.V.B.B. (Caldo Lactosado Verde Brilhante Bile). A produção de gás foi prova confirmativa positiva.

Para coliformes totais, foi adicionado $1 \mathrm{ml} \mathrm{de}$ água no tubo de vidro contendo $9 \mathrm{ml}$ de lauril, com o tubo de Durham invertido, em seguida, adicionou-se $1 \mathrm{ml}$ de lauril com a amostra no verde brilhante. Para Coliformes fecais o mesmo procedimento foi repetido, porém, adicionado 1 $\mathrm{ml}$ da solução no caldo E. coli. Logo após, foi feita a inoculação de $100 \mu \mathrm{l}$ com a pipeta na placa de Ágar EMB (Eosin Methylene Mlue) e SS (Salmonella Shigella), e com alça de platina semeada pela técnica de esgotamento, sendo repetido por 3 vezes, totalizando 3 placas. Após estes procedimentos as placas foram incubadas em estufa a $37^{\circ} \mathrm{C}$ por 24 horas.

O resultado da contagem de colônias foi multiplicado por 10 para a obtenção de um resultado quantitativo. Esta metodologia foi realizada em todos os pontos da coleta.

\section{Resultados e Discussão}

Os resultados das análises microbiológicas demonstram a presença de bactérias patogênicas em todos os pontos de coletas (Tabela 1). Ainda, com os valores obtidos das análises microbiológicas (Gráfico 1), observou-se que existe contaminação da água, pois estas ultrapassaram o valor permitido de $500 \mathrm{UFC} / \mathrm{ml}$, estabelecido pela FUNASA (2009). Com a análise dos dados, foi verificado que o número de Coliformes fecais/100 $\mathrm{ml}$ apresentou ampla variação em certos pontos da pesquisa.

As médias dos valores correspondentes aos microrganismos, calculadas por cada amostra em todos os pontos de coleta, indicaram maior concentração de coliformes fecais na área urbanizada (Gráfico 1), pois estes valores aumentaram à proporção que os pontos de coleta se aproximaram da foz do rio.

Tabela 1. Resultado das análises microbiológicas em três pontos distintos do rio Poti, no município de Teresina, Piauí, Brasil.

\begin{tabular}{lcc}
\hline Amostras & \multicolumn{2}{c}{ Parâmetros } \\
\hline & $\begin{array}{c}\text { Coliformes fecais } \\
(\text { NMP/100 ml) }\end{array}$ & $\begin{array}{c}\text { Coliformes totais } \\
(\text { NMP/100 ml) }\end{array}$ \\
\hline P01 & Presente & Presente \\
P02 & Presente & Presente \\
P03 & Presente & Presente \\
\hline
\end{tabular}

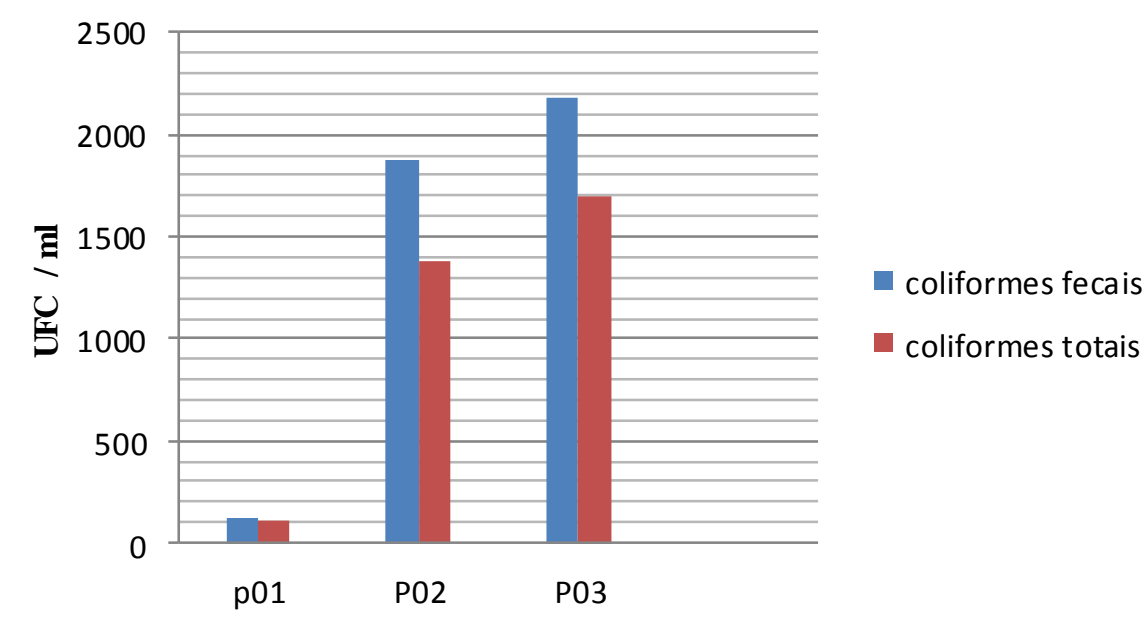

Gráfico 1. Relação da análise dos valores microbiológicos encontrados nas amostras de água do rio Poti, município de Teresina, Piauí, Brasil. 
Para a confirmação de coliformes totais e fecais foi observado através dos caldos de verde brilhante e E.C., como mostra na figura 1, pois estas bactérias modificam o meio e produzem gás. Em seguida semeadas em placas seletivas, apresentaram um crescimento representativo de colônias (Figura 2), sendo que algumas dessas amostras apresentaram números incontáveis de bactérias, respectivamente.

Para a identificação das bactérias, foram utilizados os meios de cultura IAL (Instituto Adolfo Lutz), através de provas bioquímicas, composta de nove testes, mostrados na tabela 2.

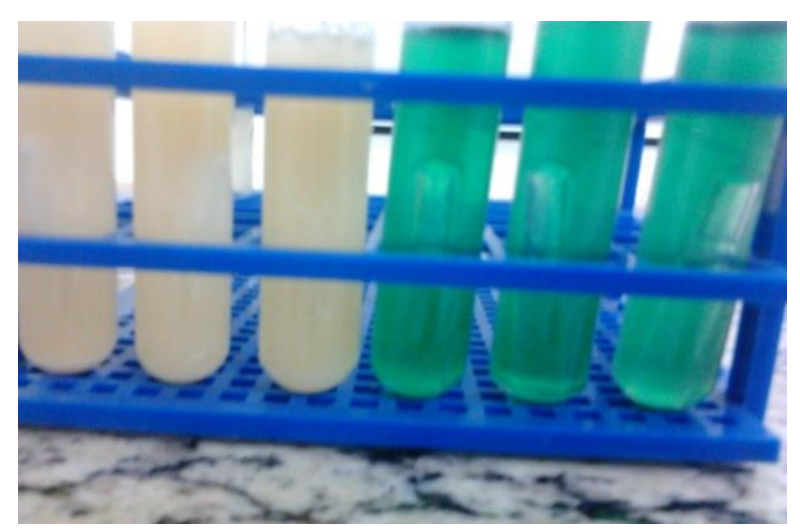

Figura 1. Confirmação da presença de coliformes fecais e totais respectivamente em caldo verde brilhante e E.C das amostras de água coletadas em três pontos do rio Poti, município de Teresina, Piauí, Brasil.
Com a identificação desses microrganismos, é possível reconhecer e distinguir as doenças que acometem os seres humanos. As mais comuns e conhecidas são as gastroenterites, que tem como principal causa a ingestão de água contaminada por bactérias, sendo comum, sobretudo, em países onde o saneamento básico é precário.

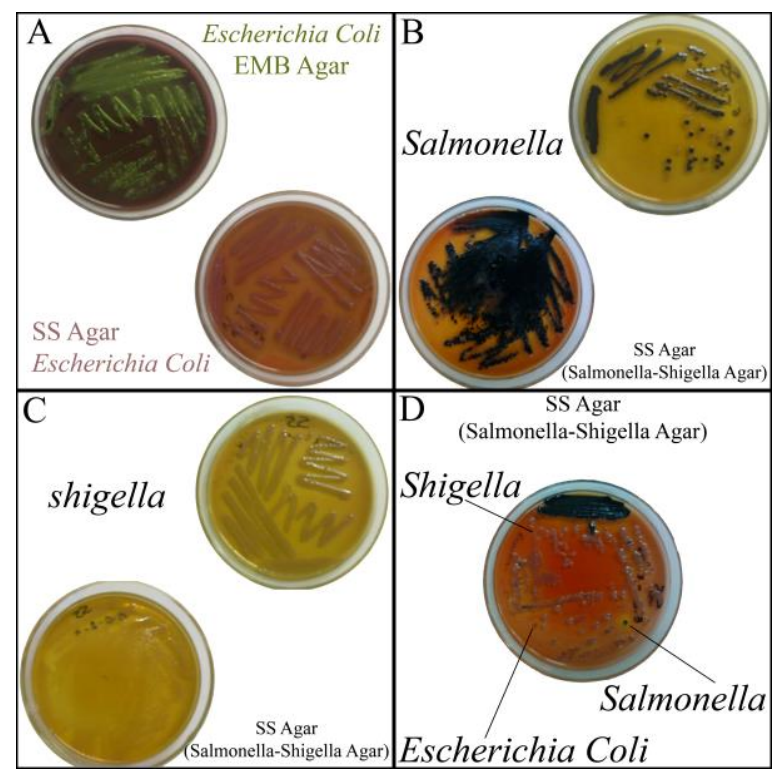

Figura 2. Crescimento bacteriano em meios de cultura seletivos. Meios de Ágar SS e EMB, utilizados para cultura de (A) Shigella, (B) salmonella e (C e D) para Escherichia coli.

Tabela 2. Identificação das bactérias obtida de acordo com a utilização do meio de cultivo IAL.

\begin{tabular}{|c|c|c|c|c|c|c|c|c|c|}
\hline Bactérias/provas & Indol & Lactose & Glicose & Gás & $\begin{array}{c}\text { Fenilala- } \\
\text { nina }\end{array}$ & Urease & $\mathrm{H} 2 \mathrm{~S}$ & Lisina & $\begin{array}{l}\text { Motilid- } \\
\text { ade }\end{array}$ \\
\hline E. coli & + & + & + & + & - & - & - & + & + \\
\hline Shigella spp & + & - & - & + & - & - & - & - & - \\
\hline Salmonella ssp & - & - & + & + & - & - & + & + & + \\
\hline
\end{tabular}

De acordo com a ANVISA (2013), a família Enterobacteriaceae é constituída por um grande grupo de bacilos Gram negativos. Estes são comumente encontradas no solo, água, frutas, vegetais e produtos de origem animal, como a carne e ovos. Muitas espécies são patogênicas para o homem, causando diversas enfermidades como as diarréias, infecções em feridas e queimaduras, infecção no trato urinário e respiratório, septicemia e meningite. Algumas, ainda, são consideradas enteropatogênica, por causarem preferencialmente infecções gastrointestinais, normalmente transmitidas por água ou alimentos contaminados. São considerados enteropatógenos clássicos a Salmonella, Shigella spp, e as diferentes categorias diarreiogênicas de E. coli. (ANVISA, 2013).

Os parâmetros biológicos avaliados, Coliformes fecais e totais foram enquadrados de acordo com os requisitos da resolução do CONAMA no 357 (2005). Considerando que o rio Poti não foi submetido a um processo de enquadramento de classificação, esse estudo pôde enquadrar os pontos do rio onde foram coletadas 
amostras para avaliação como: P01: classe 1; P02 e p03: classe 2, já que estes estabeleceram padrões que apresentaram contagens do valor de contaminações acima do permitido.

Dias (2006) relata que a Agespisa (Águas e Esgotos do Piauí S\&A), classifica o rio Poti na classe 3. Já para Oliveira (2012), o rio Poti é classificado, conforme a resolução do CONAMA $\mathrm{n}^{\circ} 357$ (2005), em classe 2, pois apresenta parâmetros biológicos acima dos limites permitidos (1000 NMP/100 ml) nas áreas mais urbanizadas. Segundo Morais \& Silva (2012) águas em que o valor obtido na amostragem for superior a 2.500 Coliformes termotolerantes ou 2.000 Escherichia coli; onde ocorra a identificação da presença de resíduos ou despejos, inclusive esgotos sanitários, óleos, graxas; quando apresentar $\mathrm{pH}$ inferior a 6,0 ou superior a 9,0, excluído condições naturais; quando houver a ocorrência de floração de algas (aguapés) ou outros organismos, são impróprias para recreação, consumo, entre outros, até que se comprove que não oferecem riscos à saúde humana.

Para Morais \& Silva (2012), o uso recreativo no balneário Curva São Paulo apresenta condições satisfatórias de balneabilidade, mesmo no período de estiagem, pois sua ocupação urbana é baixa, por enquanto, pois esta área encontra-se em processo de urbanização, o que poderá resultar na deterioração da qualidade da água do rio. No entanto o uso recreativo no período chuvoso não se é recomendado, sendo necessário tomar providências em relação à implantação dos serviços de saneamento básico.

Para Greghi (2005), a pesquisa de Coliformes fecais e de Escherichia coli fornece com maior segurança informações sobre as condições higiênicas da água e fornece uma melhor indicação da eventual presença de enteropatógenos.

As maiores predileções dos pescadores do rio Poti são as proximidades da foz do rio, localizada no bairro Poti Velho. Isso porque, a maior centralização de poluentes e as menores correntezas da água tornam-se um atrativo para os cardumes de peixes. A pesca é praticada tanto para consumo próprio como para comercialização. O aumento da concentração de poluentes tem ocasionado prejuízos a estes pescadores, devido à baixa vazão do rio, promovendo extinção de algumas espécies (Oliveira, 2012).

\section{Conclusão}

A água do rio Poti in natura, é imprópria para o consumo devido ao elevado grau de poluição. Isso se torna um problema de saúde pública, sendo necessário que haja um maior esclarecimento da população que utiliza a água do rio para atividades do dia-a-dia, a fim de que se diminuam os riscos de contaminação por doenças veiculadas pela água. Também, é extremamente importante que sejam tomadas providências imediatas de caráter corretivo e preventivo para tentar reduzir os danos ambientais ocasionados pela poluição.

Os resultados deste estudo demonstraram a importância e urgência de se implantar um eficiente sistema de saneamento básico para toda a população de Teresina, a fim de que todos tenham acesso à água tratada para consumo, diminuindo o risco de enfermidades veiculadas por este recurso. Mais estudos, incluindo os de ordem socioeconômica, devem ser realizados para monitorar a qualidade microbiológica do rio Poti, assim como a forma de utilização destas águas pela população local.

\section{Referências bibliográficas}

ANVISA. (2013). Manual de microbiologia clínica para o controle de infecção relacionada à assistência à saúde. Ministério da Saúde, Brasília.

Bettega, J. M. P. R., Machado, M. R., Presibella, M., Baniski, G. \& Barbosa, C. d. A. (2006). Métodos analíticos no controle microbiológico da água para consumo humano. Ciência e Agrotecnologia, 30, 950954.

Damasceno, L. M. O., Andrade Júnior, A. S., Silva Dias, N., Franco, J. L. D. \& França, Ê. F. (2008). Qualidade da água do Rio Poty para consumo humano, na região de Teresina, PI. Revista Verde de Agroecologia e Desenvolvimento Sustentável, 3.

Dias, M. P. S. P. (2006). O processo produtivo na mineração de areia no Rio Poti em TeresinaPiauí: um olhar para a saúde, o trabalho e o ambiente. Faculdade de Medicina. Universidade Federal do Ceará, Ceará.

Fundação Nacional da Saúde - FUNASA. (2009). Manual prático de análise de água, 144.

Greghi, S. d. Q. (2005). Avaliação da eficiência de métodos rápidos usados para detecção de 
coliforme totais e coliforme fecais em amostras de água, em comparação com a técnica de fermentação em tubos múltiplos. Ciências dos Alimentos. UNESP, Araraquara.

Iwata, B. F. \& Câmara, F. M. M. (2007). Caracterização ecológica da comunidade fitoplânctônica no rio Poti na cidade de Teresina no ano de 2006. Congresso de Pesquisa e Inovação da Rede Norte-Nordeste de Educação Tecnológica.

Ministério da Saúde. Portaria n. 518/2004. Dispõe sobre normas e padrões de potabilidade de água para consumo humano, 28.

Ministério do Meio Ambiente, Conselho Nacional do Meio Ambiente - CONAMA Resolução nº 274/2000, 18, 70-71.

Ministério do Meio Ambiente, Conselho Nacional do Meio Ambiente - CONAMA Resolução nº 357/2005, 410, 58-63.

Ministério do Meio Ambiente, Conselho Nacional do Meio Ambiente - CONAMA Resolução no 398/2008, 111, 101-104.

Morais, R. C. d. S. \& Silva, C. E. (2012). Diagnóstico ambiental do balneário Curva São Paulo no rio Poti em Teresina, Piauí. Engenharia Sanitária e Ambiente, 17, 41-50.

Moura, A. C., Assumpção, R. A. B. \& Bischoff, J. (2009). Monitoramento físico-químico e microbiológico da água do Rio Cascavel durante o período de 2003 a 2006. Arquivos do Instituto Biológico, 76, 17-22.
Oliveira, L. N. (2012). Estudo da variabilidade sazonal da qualidade de água do rio Poti em Teresina e suas implicações na população local. Master of Science. Universidade Federal do Piauí, Teresina.

Pereira, R. S. (2004). Poluição hídrica: causas e consequencias. Revista Eletrônica de Recursos Hídricos, 20-36.

Resolução CONAMA № 357/2005 - "Dispõe sobre a classificação dos corpos de água e diretrizes ambientais para o seu enquadramento, bem como estabelece as condições e padrões de lançamento de efluentes, e dá outras providências." 53, 5863, 2005.

Resolução CONAMA No 396/2008 - "Dispõe sobre a classificação e diretrizes ambientais para o enquadramento das águas subterrâneas e dá outras providências." 66, 66-68, 2008.

Sant'ana, G. R. S., Sant'ana, C. E. R., Maciel, J. R. \& R., C. C. (2009). Análise físico-química e microbiológica da água do córrego de Cascavel. Revista processos Químicos, 3, 3747.

\section{Recebido em Fevereiro 21, 2016}

Aceito em Março 30, 2016

License information: This is an open-access article distributed under the terms of the Creative Commons Attribution License, which permits unrestricted use, distribution, and reproduction in any medium, provided the original work is properly cited. 